\title{
AN OPERATIONAL SAFETY AND CERTIFICATION ASSESSMENT OF A TASAR EFB APPLICATION
}

\author{
Stefan Koczo, Rockwell Collins, Cedar Rapids, IA \\ David Wing, NASA Langley Research Center, Hampton, VA
}

\begin{abstract}
This paper presents an overview of a Traffic Aware Strategic Aircrew Requests (TASAR) Electronic Flight Bag application intended to inform the pilot of trajectory improvement opportunities while en route that result in operational benefits. The results of safety analyses and a detailed review of Federal Aviation Administration (FAA) regulatory documents that establish certification and operational approval requirements are presented for TASAR.
\end{abstract}

The safety analyses indicate that TASAR has a likely Failure Effects Classification of "No Effect," and at most, is no worse than "Minor Effect." Based on this safety assessment and the detailed review of FAA regulatory documents that determine certification and operational approval requirements, this study concludes that TASAR can be implemented in the flight deck as a Type B software application hosted on a Class 2 Portable Electronic Device (PED) Electronic Flight Bag (EFB). This implementation approach would provide a relatively low-cost path to certification and operational approval for both retrofit and forward fit implementation, while at the same time facilitating the business case for early ADS-B IN equipage. A preliminary review by FAA certification and operational approvers of the analyses presented here confirmed that the conclusions are appropriate and that TASAR will be considered a Type B application.

\section{Introduction}

NASA Langley Research Center has developed the Traffic Aware Strategic Aircrew Requests (TASAR) concept and is conducting and leading research efforts toward transition and adoption of this capability as an early NextGen flight-deck application. Utilizing network-enabled connectivity, information from avionics, including Automatic Dependent Surveillance Broadcast (ADS-B) IN traffic data, TASAR serves as a decision aid to the pilot for route improvement opportunities during flight to take advantage of changing conditions in the airspace environment. [1][2][3][4]

Rockwell Collins is supporting NASA in safety analyses and identifying requirements toward successful certification and operational approval of TASAR, which are examined in detail in this paper. The TASAR EFB application is currently being developed by NASA to leverage emerging flight deck technologies for cost-benefits to current flight operations. Among the systems and technologies that comprise or support TASAR are flight-optimizing software algorithms, a software hosting device such as a PED EFB, Automatic Dependent Surveillance Broadcast (ADS-B) IN and other sources of traffic information, and additional ground-based information via data link, internet connectivity, etc. TASAR seeks to provide cost-beneficial optimization with respect to the current flight plan, taking traffic and other constraints into account. Using these information sources, the TASAR application has the ability to react in an agile manner to changes in the external airspace environment (e.g., adverse weather, winds, airspace constraints, and/or improved timeliness and accuracy of information about factors that affect the aircraft's execution of its flight plan).

The TASAR EFB application (referred to hence as TASAR) is a flight deck-based decision support tool that seeks to identify and recommend trajectory improvement opportunities to the pilot that have high probability of approval by Air Traffic Control (ATC). Utilizing available information of own-ship flight status, route, and airspace environment (e.g., proximate traffic, weather, winds, special activity airspace status), TASAR seeks to identify and recommend candidate trajectory improvements for consideration by the pilot that have higher probability of ATC approval. The pilot, at his or her discretion, can choose to issue a change request to ATC based on TASAR recommended trajectory change candidates.

Prior to recommending trajectory change candidates to the pilot, TASAR performs the 
following: 1) it evaluates the proposed trajectory changes against available on-board traffic data for potential conflicts, and 2) it may account for known ATC sector rules and own-ship's position relative to the sector. Recommended trajectory change request candidates from TASAR are expected to have the following characteristics:

1) Meet operational goals for the flight, as provided by pilot preferences and route constraints that are input to TASAR

2) Provide improvement to the current flight plan in terms of time and / or fuel saved or other desired attributes such as passenger comfort.

3) Have a high potential for approval by ATC by considering ATC factors in the identification process

TASAR change request candidates are advisoryonly to the pilot, and the pilot has full discretion on whether or not to use a TASAR-provided trajectory change as a change request to ATC. Pilot training will emphasize that aviate-navigate-communicate priorities and normal procedures for coordination with ATC are to be followed as in today's operations. The pilot has responsibility to evaluate TASARprovided trajectory change candidates for operational acceptability before making a change request to ATC to minimize spurious requests from being made. ATC retains authority to approve trajectory changes, and ATC will not approve change requests from the pilot that do not meet ATC constraints and requirements.

This paper is organized into two major analysis sections. The first section presents the TASAR Operational Safety Assessment. The second section presents an analysis of EFB Standards Adherence. The paper concludes with feedback from FAA certification and operational approval officials on these analyses and a summary of additional activities underway to support early implementation of the TASAR concept.

\section{TASAR Operational Safety Assessment}

Two safety assessment methodologies were used that are compliant with the Federal Aviation Administration's Safety Management System (SMS) for certification and approval of aircraft avionics functions such as TASAR:
1) A traditional safety assessment using Aviation Recommended Practice (ARP) 4761 [5], Advisory Circular (AC) 25-1309 [6] and AC 23-1309 [7] for Part 25 and Part 23 aircraft operations (Method 1)

2) An Operational Safety Analysis (OSA) based on RTCA DO-264 / EUROCAE ED-78A [8] (Method 2).

This section provides a high-level description and application of the two safety methodologies, which provided complementary results and thus strengthen the determination of the TASAR Failure Effects Classification. In analyzing the safety case, the "intended function" of TASAR must be considered in order to properly assess the operational hazards associated with the application. The TASAR intended function is described after the following brief overview of the two safety assessment methods.

\section{Method 1 Safety Assessment}

Method 1 represents the traditional safety analysis approach [5][6][7] to determine the Failure Effects Classification of the aircraft function under consideration, in this case, TASAR. This leads to the assignment of the Design Assurance Level, which then determines the hardware and software development processes that must be followed and the requirements that must be met for certification and operational approval of the system.

Method 1 performs the following steps relative to the intended function of the new system capability, i.e., TASAR:

1) Evaluate the intended function per phase of flight

2) Identify failure events, e.g., loss of function; undetected errors

3) Examine the effect of these failures on aircraft, flight crew, and Air Traffic Control (ATC)

4) Determine the Hazard Classification, e.g., Major, Minor, No Effect

5) Determine frequency of occurrence, e.g., per flight hour, per operation

6) Provide rationale for hazard assessment.

\section{Method 2 Safety Assessment}

Method 2 [8] represents an analysis approach that is well-suited for allocating safety requirements 
of avionics functions consisting of multiple systems. This allows a more balanced allocation of safety requirements across systems and sub-systems, which is particularly beneficial for higher criticality systems. While an excellent approach for systemsof-systems analysis, it is not as well suited for lower criticality systems, e.g., "Minor," which puts excessive emphasis on quantitative analysis of operational effects such as workload that are often highly subjective and difficult to assess. A strength of Method 2 is that it provides a more comprehensive assessment of operational hazards, which is why this analysis method was used to complement Method 1.

Method 2 follows these evaluation steps:

1) Perform an Operational Hazard Assessment

a) Identify Operational Hazards

b) Determine the worst credible outcome of the Operational Hazard, i.e., the Operational Effect, e.g., collision, loss of separation, workload

c) Determine the Severity Classes for each Operational Effect, e.g., Catastrophic, Major, Minor, and identify the maximum allowable probability of occurrence of the Operational Effect

d) Determine the Effects Probabilities, which represent probabilities of available mitigation(s) to the system that reduce the probability of occurrence of the Operational Effect that may result from the Operational Hazard

e) Assign Safety Objectives, which represent the probability of occurrence of each Operational Hazard that is allowable for ensuring the safety of the application

f) Identify External Mitigation Means, i.e., barriers external to the application that reduce the adverse effects and impact to safety when Operational Hazards occur.

2) Allocate Safety Objectives and Safety Requirements

a) Identify Abnormal Events, i.e., failures due to human actions, and Basic Causes, i.e., failures due to actions by automation that are internal to the application that could lead to the occurrence of each Operational Hazard

b) Identify Internal Mitigation Means, i.e., barriers internal to the application that reduce the probability of the Operational Hazard from occurring in order to achieve the required Safety Objective

c) Allocate Safety Requirements to the subfunctions comprising the application.

\section{TASAR Intended Function Description}

The intended function of TASAR, as a flight deck decision aid consisting of software automation that provides advisory-only service to the pilot, is to seek trajectory improvement opportunities over the current flight plan and to display these improvements as candidate change requests in textual form to the flight crew. A simple graphical display of the proposed route change may be used for crosschecking and verification. TASAR is expected to be implemented as a hosted software application on an EFB.

Based on inputs provided by: 1) the pilot in the form of flight objectives and optimization criteria, 2) on-board avionics systems in the form of current aircraft state, flight plan, traffic data, etc., and 3) airborne internet data connectivity, the TASAR application computes available change request candidates that may improve the current flight plan. Change request candidates are intended to have relatively high probability of ATC approval, as TASAR seeks to account for ATC factors such as traffic separation and airspace boundaries.

The pilot has full discretion on the use of TASAR-provided change request information; he can choose to use TASAR-recommended change request candidates as part of a change request to ATC, or he can choose to ignore them. TASAR can be manually inhibited at any time, for any reason. Thus, in the event of observed spurious behavior of TASAR due to any system failure, inaccurate data obtained via network enabled information sources, or TASAR being a source of distraction to the flight crew, the pilot can simply inhibit or ignore TASAR. By following their training, the pilot can manage the use of TASAR in such away so that TASAR will not result in any workload increase in the flight deck.

TASAR is strictly a supplemental system intended to provide operational benefits without adversely impacting safe operations, and it does not replace any aircraft system or procedure needed for flight operations. The TASAR display is passive with no 
graphical display of traffic or audible alerting. Loss of the TASAR EFB application for any reason does not affect the Minimum Equipment List (MEL) and does not affect normal flight operations.

TASAR information sources may include:

1) Own-ship systems (aircraft state, auto-flight settings, flight plan and performance information from Flight Management System (FMS), Electronic Flight Instrument Systems (EFIS), etc.)
2) Traffic data via ADS-B IN, Traffic Information Service Broadcast (TIS-B), or other sources

3) Airspace constraints (sector boundaries, special activity airspace status, etc.)

4) Weather status / forecast

5) Wind status / forecast

6) Operator flight planning, preferences, objectives

Figure 1 illustrates the TASAR functional diagram identifying the information interfaces.

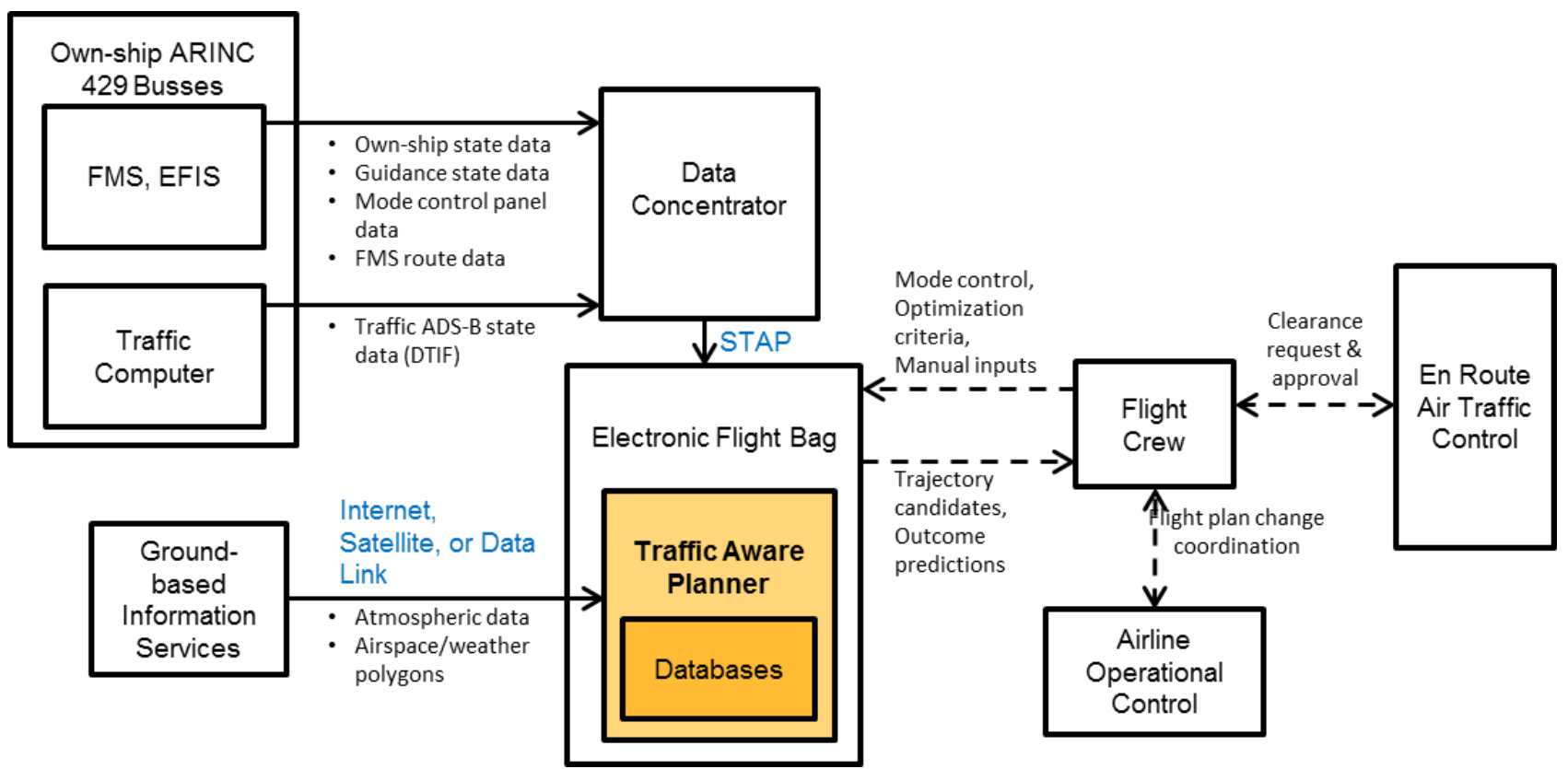

Figure 1 TASAR Functional Diagram

\section{Method 1 Safety Analysis}

The key outcome of this safety assessment process is the determination of the Failure Effects Classification for TASAR. The Failure Effects Classification then determines the development and validation requirements and processes to be followed in integrating TASAR as a flight deck application for certification and operational approval.

Using this safety assessment process, applicants and certification and operational authorities (i.e., FAA aircraft certification and flight standards organizations) follow the process of assessing the new application and attendant procedures for potential failure modes and their impact on safety.

\section{Key Factors that Influence Failure Effect Classification of TASAR}

The following list represents key factors that influence the determination of the Failure Effect Classification for TASAR:

1) TASAR is a supplemental system and thus is not relied on by critical functions supporting flight deck operations

2) TASAR is optional, i.e., not a required system for flight operations. In the event of failures of the 
TASAR system, TASAR can be ignored or disabled without adversely affecting operations

3) TASAR has no MEL requirement

4) TASAR can be manually inhibited at any time, for any reason:
a) Detected failure of the TASAR application
b) Detected failure of the host EFB
c) Spurious or inconsistent performance of recommended change requests
d) Distracting effects of TASAR to the pilot

5) Presence or loss of TASAR does not change responsibilities of the pilot for flight operations

6) TASAR is an "advisory-only" system (i.e., does not provide guidance information):

a) Pilot is not reliant on TASAR outputs to any extent to perform flight operations

b) Pilot can choose to utilize or ignore change requests candidates recommended by TASAR as part of change requests to ATC
7) Change request procedures are unchanged:

a) Pilot must direct all change requests to ATC using conventional means

b) ATC is responsible for reviewing request for acceptability, including separation from traffic

c) ATC either: 1) approves request and issues clearance, 2) provides an amended clearance, 3) defers request to next controller, or 4) denies request

8) Undetected, misleading information associated with TASAR outputs, i.e., with one or more candidate change request recommendations, will have "No Effect" on the pilot, aircraft, and/or ATC. Whether due to failure of one of the TASAR sub-systems and associated automation processing, or the result of inaccurate data obtained from ground-based or flight deck systems, spurious change requests are mitigated by flight crew inspection of the recommended trajectory change and by mitigations associated with the existing change request process.

\begin{tabular}{|c|c|c|c|c|c|c|c|}
\hline $\begin{array}{l}\text { Probability } \\
\text { (Quantitative) } \\
\text { [Not to Exceed] }\end{array}$ & $\begin{array}{c}\text { FAA } \\
\mathrm{AC}\end{array}$ & 1 & $10^{-3}$ & & $10^{-5}$ & $10^{-7}$ & $10^{-9}$ \\
\hline \multirow{2}{*}{$\begin{array}{l}\text { Probability } \\
\text { Descriptive }\end{array}$} & FAA & $\mathrm{N} / \mathrm{A}$ & Prol & able & \multicolumn{2}{|c|}{ Improbable } & $\begin{array}{c}\text { Extremely } \\
\text { Improbable }\end{array}$ \\
\hline & JAA & $\mathrm{N} / \mathrm{A}$ & Frequent & \begin{tabular}{|c|} 
Reasonably \\
Probable
\end{tabular} & Remote & Extremely Remote & $\begin{array}{c}\text { Extremely } \\
\text { Improbable }\end{array}$ \\
\hline \multirow{2}{*}{$\begin{array}{l}\text { Failure Condition } \\
\text { Hazard Severity } \\
\text { Classification }\end{array}$} & FAA & None & Min & inor & Major & $\begin{array}{c}\text { Hazardous/ } \\
\text { Severe Major }\end{array}$ & Catastrophic \\
\hline & JAA & None & \multicolumn{2}{|c|}{ Mínor } & Major & Hazardous & Catastrophic \\
\hline \multirow{2}{*}{$\begin{array}{l}\text { Effects on } \\
\text { Aircraft and } \\
\text { Occupants }\end{array}$} & FAA & $\begin{array}{l}\text {-No Safety } \\
\text { Effect }\end{array}$ & $\begin{array}{l}\text {-Does not sigh } \\
\text { reduce airp } \\
\text { (Slight incry } \\
\text { margins) } \\
\text { - Crew actior } \\
\text { capabilities } \\
\text { increase in } \\
\text { workload) } \\
\text { - Some incon } \\
\text { occupants }\end{array}$ & $\begin{array}{l}\text { nificantly } \\
\text { ane safety } \\
\text { ase in safety } \\
\text { s well within } \\
\text { (Slight } \\
\text { rew } \\
\text { enience to }\end{array}$ & \multicolumn{2}{|c|}{$\begin{array}{l}\text { - Reduce capability of airplane or crew to } \\
\text { cope with adverse operating conditions } \\
\text { - Significant reduction in safety margins } \\
\text { - Significant increase in crew workload } \\
\text { Severe Cases: } \\
\text { - Large reduction in safety margins } \\
\text { - Higher workload or physical distress on } \\
\text { crew - can't be relied upon to perform } \\
\text { tasks accurately } \\
\text { - Adverse effects on occupants }\end{array}$} & $\begin{array}{l}\text { - Conditions which } \\
\text { prevent } \\
\text { continued safe } \\
\text { flight and } \\
\text { landing }\end{array}$ \\
\hline & JAA & $\begin{array}{l}\text { - No Safety } \\
\text { Effect }\end{array}$ & $\begin{array}{l}\text { R OSA } \\
\text { Area }\end{array}$ & $\begin{array}{c}\text { Operating } \\
\text { limitations } \\
\text {-Emergency } \\
\text { procedures }\end{array}$ & $\begin{array}{l}\text { - Significant } \\
\text { reduction in } \\
\text { safety margins } \\
\text {-Difficult for crew } \\
\text { to cope with } \\
\text { adverse } \\
\text { conditions } \\
\text {-Passenger } \\
\text { injuries }\end{array}$ & $\begin{array}{l}\text { - Large reduction in } \\
\text { safety margins } \\
\text { - Crew extended } \\
\text { because of workload } \\
\text { or environmental } \\
\text { conditions } \\
\text { - Serious or fatal } \\
\text { injury to small } \\
\text { number of } \\
\text { occupants }\end{array}$ & $\begin{array}{l}\text { - Multiple deaths, } \\
\text { usually with loss } \\
\text { of aircraft }\end{array}$ \\
\hline System DAL & - & $\bar{E}$ & \multicolumn{2}{|c|}{ D } & $\bar{C}$ & $\mathrm{~B}$ & $A$ \\
\hline
\end{tabular}

Figure 2 Acceptable Risk versus Potential Effects (as defined for Civil Aviation) (from [6])

\section{Failure Effects Classification}

Figure 2 (assembled from requirements specified in [6]) summarizes the mapping of the "Effects" due to failures and the allowable "Probability of
Occurrence" that serve as the basis in determining the Failure Effects Classification of the planned application (i.e., TASAR). The applicant for the new capability and FAA certification and operational 
approval personnel use Figure 2 to jointly determine the Failure Effects Classification of the system under consideration. Based on the key factors identified in the previous section, our safety analysis concludes that TASAR can be safely developed and implemented with a "No Effect" designation. Potentially TASAR could rise to "Minor Effect" in the event of inconsistent candidate change request recommendation(s), which could result in workload issues for the pilot and/or ATC.

Workload issues are not anticipated to be an issue for the pilot's use of TASAR, as the pilot can simply ignore TASAR for any reason. Through proper training in the purpose of TASAR, pilots will not likely allow themselves to be distracted or be adversely influenced in using TASAR while conducting flight operations. From an ATC perspective, controllers will continue to conduct the change request process as in today's operation and are not expected to experience a workload issue due to TASAR. The only concern may be if a large percentage of users equip with TASAR, potentially causing the total number of requests to increase. However, the rate of adoption of new technology is typically gradual, which would mitigate this effect. In addition, proper design of TASAR is expected to result in informed, pertinent change requests that have an increased probability of ATC approval and thus are not expected to adversely impact the change request process or controller workload.

Final determination of the Failure Effects Classification for TASAR requires a dialog between the applicant and FAA certification and operational approval authorities using the results of the safety analysis, resulting in a final designation by FAA. Initial feedback from these FAA authorities is presented at the end of the paper.

\section{Internal Mitigation Means}

The TASAR application itself provides additional inherent capabilities that further reduce the possibility of unintended adverse effects and are expected to enhance the usability of the application. The following TASAR capabilities further serve to strengthen and support the "No Effects" Failure Effects Classification for TASAR:

1) In order to prevent lengthy, complex change requests from the pilot to ATC, TASAR utilizes standard navigation databases and places limits on excessive waypoints included in the recommended change requests it provides.

2) TASAR displays flight path change opportunities using standard flight planning textual depictions to facilitate voice communications.

3) TASAR may include capabilities to assess sector complexity and own-ship's proximity to the sector boundary in order to only recommend change requests that have a high likelihood of being approved by ATC.

\section{Procedural Mitigations Available to the Pilot}

The following represent additional mitigations available to the pilot via procedural means:

1) A characteristic of TASAR is that there is no "recovery" time required for the flight crew associated with its use. In other words, in using TASAR, the pilot remains on an ATC-cleared trajectory at all times. In the event of a TASAR system fault, the pilot need only remain on the current clearance while disregarding the TASAR display. A simple reset of TASAR, or by simply choosing to ignore TASAR inputs (e.g., by not looking at the TASAR display) allows the pilot to continue to focus on aviate-navigatecommunicate priorities in conducting flight operations (whether during normal operations or in the event of abnormal or emergency situations).

2) The pilot has responsibility to evaluate TASARprovided Trajectory change request candidates for operational acceptability before making a change request to ATC, providing cross-check opportunities to detect spurious or false Trajectory change request candidates being offered by TASAR.

3) Aircraft systems, e.g., FMS, weather radar, provide higher integrity information allowing quick check on acceptability and performance impacts of TASAR recommended change requests.

\section{Phase of Flight Considerations}

TASAR is intended for use primarily during enroute operations. Change request candidates are offered by TASAR during the latter portion of climb, while en-route, and to a lesser extent, into the early portion of descent operations. TASAR is thus used 
primarily during non-critical phases of flight, i.e., above $10,000 \mathrm{ft}$.

\section{Information Source Quality}

Information source quality and integrity must be commensurate to support the Failure Effects Classification. Due to the "No Effect / Minor Effect" Failure Effects Classification anticipated for TASAR, TASAR input information quality and integrity requirements are driven more by operational use issues than by safety considerations. Low quality or misleading information can result in poor recommendations to the pilot for candidate change requests. The net effect, however, is simply that TASAR will not be as effective in achieving envisioned operational benefits (e.g., time or fuel saved).

\section{Undetected Failure - Worst Case Effect}

In the event of an undetected failure of the TASAR automation, inefficient routing is the only adverse outcome. Existing mitigation of any safety hazards is provided by ATC, as already is done for change requests today without TASAR.

The Safety Analysis using Method 2 described in the next section takes a closer look at specific failure modes of TASAR, complementing the results from this section.

\section{Method 2 Safety Analysis - Operational Safety Assessment Process}

This section provides the safety analysis of TASAR using Method 2 [8] by applying the "bowtie" model illustrated in Figure 3 . The system of interest, in this case the TASAR application, is represented in the left-hand side of the bow-tie. The external environment in which the application operates, including environmental conditions (e.g., airspace influences, weather, traffic) and the external systems that are part of the overall operational concept (e.g., aircraft systems and ATC systems) are represented by the right-hand side of the bow-tie.
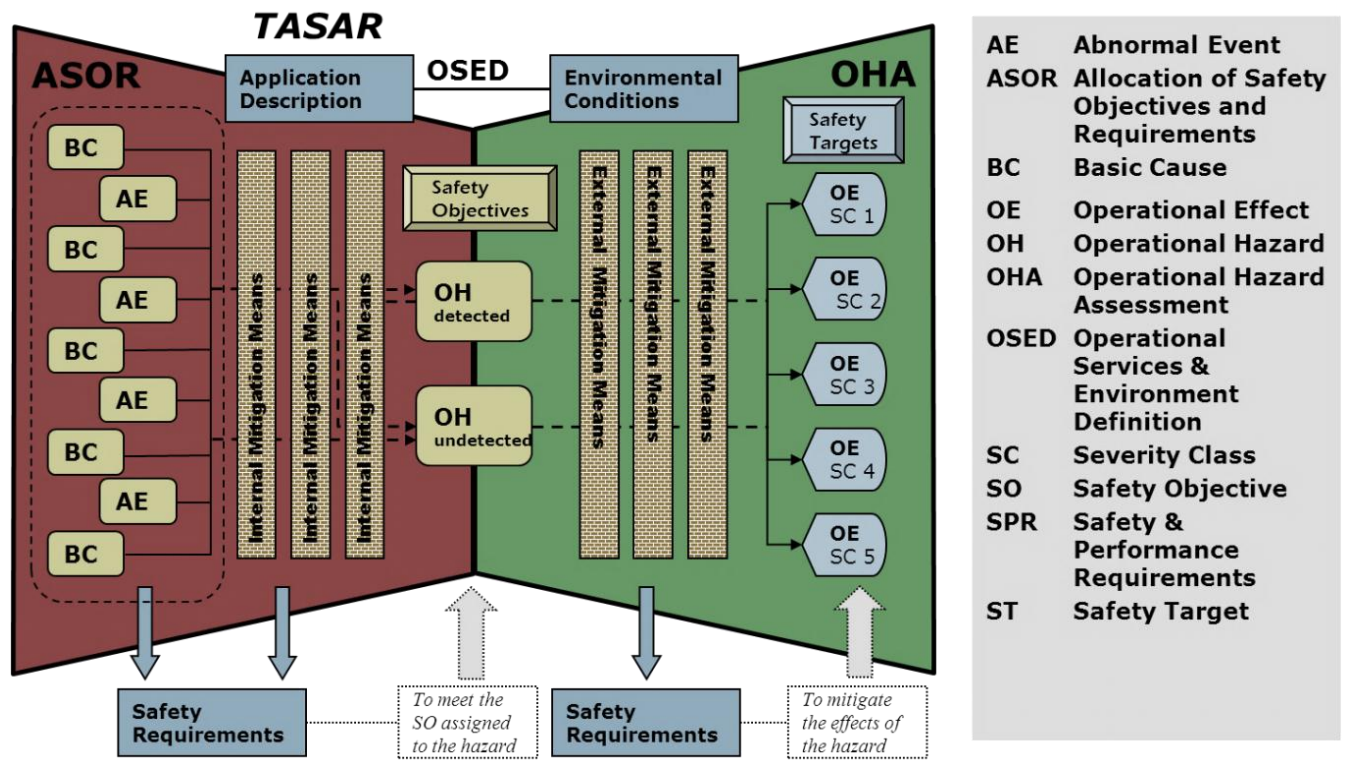

Figure 3 Operational Safety Assessment Process - Method 2

The OSA process consists of the following major sub-processes: 1) the Operational Hazard Assessment (OHA), and 2) Allocation of Safety Objectives and Requirements (ASOR).

In performing the OHA, the first step is to use operational experts from all stakeholder communities to identify potential Operational Hazards that may result from the application (e.g., TASAR). For each identified Operational Hazard, the next step is to determine the worst "credible" outcome, also referred to as the Operational Effect (OE). Examples are collision, loss of separation, and workload. Figure 4 provides the mapping of Operational Hazards to the associated Operational Effects due to each hazard class. 


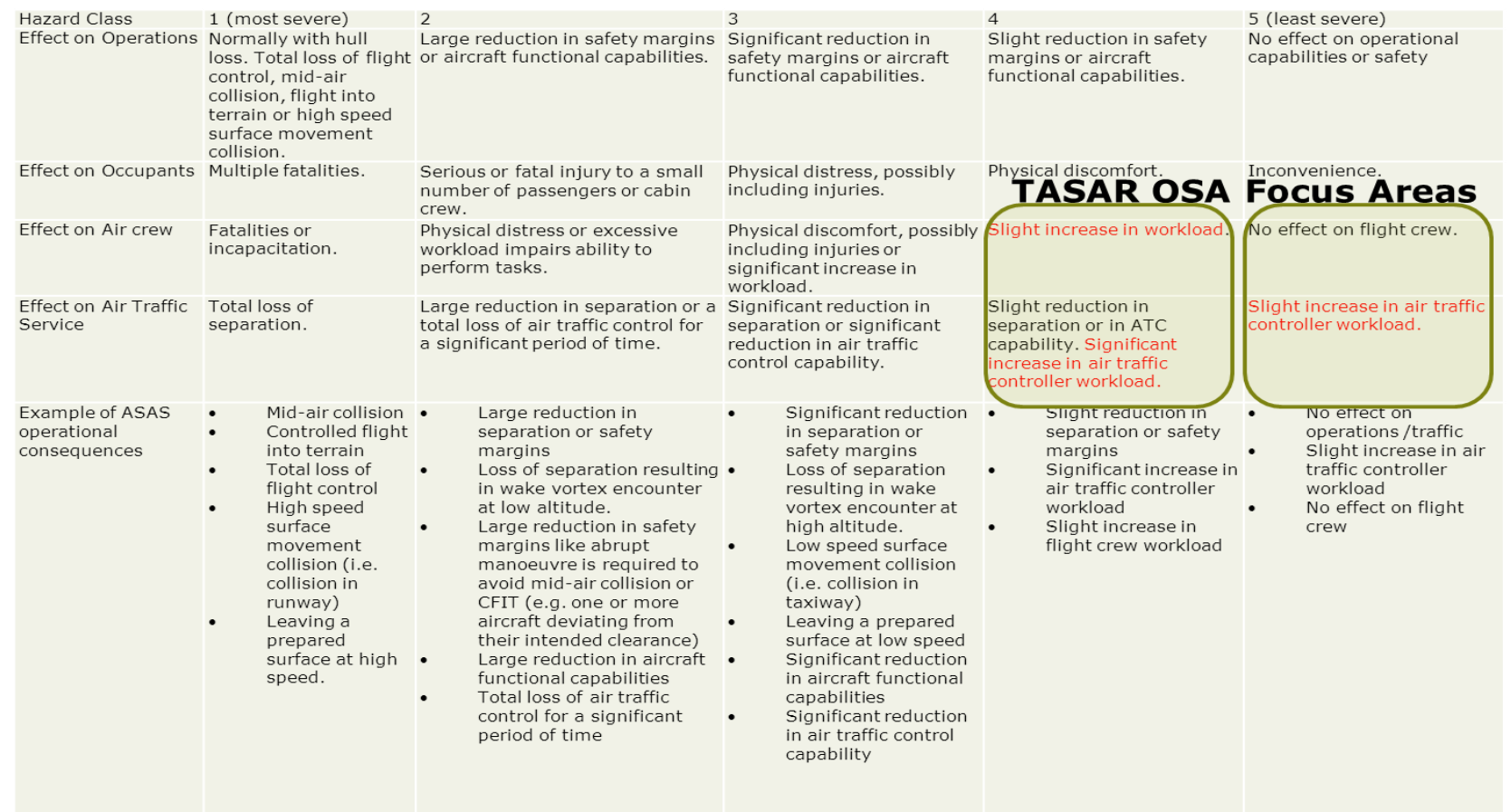

Figure 4 ED78A/DO264 Based Hazard Classification Matrix

For each Operational Hazard and associated Operational Effect, the Severity Class is determined. Severity Classes include catastrophic, severe major, major, minor, and no effect. For each Operational Effect and associated Severity Class, a "Probability of Occurrence" not to be exceeded to assure safety of operations is established, ranging from $10^{-9}, 10^{-7}$, $10^{-5}, 10^{-3}$, etc. for occurrence of the Operational Effect. The Operational Effects and Severity Classes are noted in Figure 3 on the right side of the bow-tie.

\section{Potential Operational Hazards and Mitigations}

Figure 5 provides a summary of the Operational Hazards (denoted as $\mathrm{OH}-\mathrm{x}, \mathrm{x}=1$ to 7 ) that were identified for TASAR. Also included is a brief description of the Operational Hazard and the major mitigation(s) that were identified. Based on the Operational Hazards identified and evaluated in Figure 5, it is evident that the region of interest for TASAR falls under the highlighted areas in Figure 4 (i.e., Hazard Class 4 and 5). The highlighted regions represent "No Effect" and "Minor" Failure Effect Classifications. This determination is further strengthened by the availability of strong External
Mitigation Means (right side of Figure 3) that are already in place as part of today's change request procedure. Thus, only an "abbreviated" OSA was conducted, focusing on identifying Operational Hazards that could potentially occur when using TASAR.

Identification of TASAR Operational Hazards serves to complement the analysis results of the safety analysis results using Method 1. More specific details on both these safety analysis methods as applied to TASAR, and identification of Abnormal Events and Basic Causes that may lead to the occurrence of Operational Hazards for TASAR are found in [9]. Consistent with the safety assessment used in Method 1, the Operational Safety Assessment used here (i.e., Method 2) the most likely Failure Effect Classification for TASAR would be "No Effect" or at most "Minor". With either of these classifications, TASAR is amenable for integration as an EFB application. The standards adherence requirements of EFB applications are discussed in the next section. 


\begin{tabular}{|c|c|c|}
\hline Operational Hazard & Description & Mitigation \\
\hline $\begin{array}{l}\mathrm{OH}-1 \text { : TASAR could provide one or } \\
\text { more change request candidates that } \\
\text { are not conflict free }\end{array}$ & $\begin{array}{l}\text { This Operational Hazard is the result of poor } \\
\text { information quality and/or mixed ADS-B Out equipage } \\
\text { environment, where not all traffic is known }\end{array}$ & $\begin{array}{l}\text { ATC provides separation assurance } \\
\text { independent of TASAR }\end{array}$ \\
\hline $\begin{array}{l}\mathrm{OH}-2 \text { : Pilot could misinterpret TASAR } \\
\text { candidate change request and could } \\
\text { unknowingly request a trajectory } \\
\text { clearance that is not conflict free or } \\
\text { could lead toward hazardous airspace }\end{array}$ & $\begin{array}{l}\text { TASAR could "inadvertently" mislead or confuse the } \\
\text { pilot who could then misrepresent the TASAR change } \\
\text { request to ATC }\end{array}$ & $\begin{array}{l}\text { ATC provides separation assurance } \\
\text { independent of TASAR } \\
\text { Aircraft safety systems (e.g., Traffic Alert and } \\
\text { Collision Avoidance System, weather radar, } \\
\text { Terrain Awareness and Warning System) } \\
\text { provide hazard detection and alerting }\end{array}$ \\
\hline $\begin{array}{l}\mathrm{OH}-3 \text { : Pilot could follow the wrong } \\
\text { trajectory clearance following receipt of } \\
\text { amended clearance from ATC }\end{array}$ & $\begin{array}{l}\text { Pilot could request a change recommended by the } \\
\text { TASAR system, and although ATC amends the request, } \\
\text { TASAR-induced confusion could lead the pilot to follow } \\
\text { the request instead of the clearance }\end{array}$ & $\begin{array}{l}\text { ATC monitors execution and intercedes (same } \\
\text { as today) } \\
\text { Pilot training } \\
\text { Pilot crosschecks clearance with FMS }\end{array}$ \\
\hline $\begin{array}{l}\mathrm{OH}-4 \text { : ATC, somehow being aware of } \\
\text { TASAR capability for the aircraft / pilot } \\
\text { requesting a change request to the } \\
\text { flight plan, could be less vigilant to } \\
\text { provide separation assurance }\end{array}$ & $\begin{array}{l}\text { The concern is whether ATC could become complacent } \\
\text { over time, when receiving TASAR requests } \\
\text { (note that TASAR equipage is not specified on filed } \\
\text { flight plans or included in pilot-request verbiage) }\end{array}$ & $\begin{array}{l}\text { Existing ATC procedure to check all requests for } \\
\text { separation } \\
\text { Note: This is not a credible Operational Hazard } \\
\text { because separation assurance is ATC's primary } \\
\text { responsibility }\end{array}$ \\
\hline $\begin{array}{l}\text { OH - 5: TASAR could provide numerous } \\
\text { spurious and/or inconsistent series of } \\
\text { change request candidates leading to } \\
\text { multiple requests }\end{array}$ & $\begin{array}{l}\text { If change request recommendations are not reinforced } \\
\text { from one request to the next, multiple counteracting } \\
\text { requests could be issued } \\
\text { These requests could become a nuisance issue and } \\
\text { potentially could lead to a workload issue for ATC }\end{array}$ & $\begin{array}{l}\text { ATC denies user requests if workload is too } \\
\text { high }\end{array}$ \\
\hline $\begin{array}{l}\mathrm{OH}-6 \text { : TASAR could recommends a } \\
\text { trajectory candidate with } \\
\text { miscomputation of fuel burn }\end{array}$ & $\begin{array}{l}\text { Pilot reliance on TASAR fuel burn estimates (presented } \\
\text { to help pilots choose between multiple request } \\
\text { options) could lead to greater fuel burn than expected }\end{array}$ & Pilot crosscheck of FMS prediction of fuel burn \\
\hline $\begin{array}{l}\text { OH - 7: Unexpected weather could } \\
\text { develop on TASAR recommended route } \\
\text { after ATC approval }\end{array}$ & $\begin{array}{l}\text { Unexpected weather could require additional change } \\
\text { requests and therefore more fuel to be used }\end{array}$ & $\begin{array}{l}\text { Normal procedures for responding to } \\
\text { unexpected weather }\end{array}$ \\
\hline
\end{tabular}

Figure 5 TASAR Operational Hazards and Mitigations

\section{EFB Standards Adherence}

The second half of this paper focuses on 1) EFB standards adherence requirements for the certification and operational approval of TASAR, 2) identification of artifacts needed in support of the certification basis and means of compliance of approval of TASAR, and 3) review of the elements of a Project Specific Certification Plan (PSCP) that may need to be followed as part of the eventual certification and operational approval of TASAR as a fielded product. This information was developed in support of NASA's TASAR research program as preliminary steps toward a potential future certification project of TASAR, but in itself does not constitute an actual certification program.

\section{Current EFB Industry Trends}

Before describing the EFB standards adherence requirements for TASAR, this section provides an overview of current trends in the aviation industry's use of EFB to provide additional functionality and applications to the flight deck.

1) EFBs and their software applications provide (or are anticipated to provide) a retrofit path for new, increasingly more capable flight deck capabilities. The increased ability of commercial off-the-shelf (COTS) PEDs is providing impetus to add new capabilities economically.

2) Airlines are beginning to see cost-benefits of EFBs, often with different business cases to equip. They see reduced pilot workload, simplified flight operations, and greater situational awareness as key benefits. 
As increasingly more capable EFB applications are identified and being considered for integration in the flight deck, these EFB applications are transitioning from standalone, low-certification level (e.g., Minor) hosted applications on a PED EFB, to applications that interface with higher-criticality avionics systems (read-only, transmit-only, or both), while at the same time also being connected to external networks. Consequently, FAA and industry must require sufficient protections to prevent interference by the PED EFB to avionics systems (e.g., Electro-Magnetic Interference (EMI) protection), provide cyber security, and require an Aircraft Interface Device (AID) that serves as a trusted interface between more critical avionics systems and the lower criticality COTS PED EFB. From the TASAR perspective, by requiring a read-only interface, and being an advisory-only system that can be disabled at any time, this allows a relatively low threshold for approval.

It is reiterated that it is the intended function of an EFB application that is paramount in determining the extent to which EFBs can be utilized to provide functions in the flight deck. Based on feedback from FAA approvers, TASAR, as currently defined, falls well within the acceptable use of EFBs to provide operational benefits to the end user.

3) EFBs are becoming sought-after, low-cost flight deck tools for improving situational awareness and leading to improved pilot decision making. They allow the flight crew to connect in real time to the rest of the world (e.g. TASAR via data link connectivity to internet information sources for weather, traffic, airspace status data, etc.).

4) While EFB hardware requirements and specifications remain important, hardware is expected to become commoditized, with future focus shifting to development of more robust software applications (refer to FAA AC 120-76B [10] for definitions and approval requirements associated with EFB hardware and software).

6) The latest technological development for Class 2 EFBs is their ability to interface with aircraft systems and to provide an access point to wireless communications pipelines (similar to those planned for TASAR data connectivity).
7) Once ADS-B IN becomes available for display in aircraft, benefits of EFB may become significant. However, depending on the intended function, this likely raises the criticality for such EFB software applications, which may go beyond "Minor" of Type A and Type B applications.

TASAR already utilizes ADS-B IN traffic information as part of its computation of conflict free trajectory candidates. However, it does not display own-ship or other traffic to the pilot and thus remains closely aligned with Type B applications, i.e., it consists of processing algorithms similar to those associated with Type $\mathrm{B}$ applications. TASAR is expected to be less critical than Type B applications associated with Weight and Balance, and Performance calculations.

8) There is a likelihood that EFB systems with hosted Type A and Type B applications and with approved software (those designed using DO178B) will be integrated in some installations. This likely requires a dual-processor EFB architecture, allowing partitioning of higher and lower criticality software applications. For example "approved" DO-178B certified software applications to be allocated to one EFB processor running DO-178B-certified Linux Operating System (OS), and Type A and Type B "hosted" applications (developed without DO-178B) running on a non-certified Windows OS. Alternate architectures and approaches can be considered if equivalent in robustness.

9) TASAR, as a hosted application, may be integrated with other software applications (some hosted and perhaps some approved) and may be installed in a variety of EFB platforms including some with certified OS. The manner of integration and hosting of TASAR may affect the software certification requirements of its design.

\section{Key FAA Regulatory Documents}

The following represent some of the cornerstone regulatory documents from FAA that provide guidance information and requirements that must be met in order to gain certification and operational approval for EFB-based flight deck applications. These documents were reviewed and assessed in detail in order to identify expected EFB standards adherence requirements for TASAR. These 
documents point to numerous secondary documents not listed here that contain additional approval requirements that an applicant must address as part of a certification project with FAA:

1) Title 14 of the Code of Federal Regulations (14 CFR) parts 21, 23, 25, 27, 29, 43, 91F, 91K, 121, 125 , and 135 [11]

2) Flight Standards Information System (FSIMS) 8900.1 Change 47, Vol. 4, Chapter 15 - EFB Operational Authorization Process [12]

This document provides the FAA approval perspective, providing the Principal Operations Inspector (POI) checklists followed for EFB and associated applications approval, including approval considerations for TASAR.

3) $\mathrm{AC} 120-76 \mathrm{~B}$, Guidelines for the Certification, Airworthiness, and Operational Approval of Electronic Flight Bag Computing Devices [10]

This document is intended for operators conducting flight operations under Title 14 of the Code of Federal Regulations (14 CFR) part 121, 125,135 , or 91 subpart $F$ (part 91F) and part $91 \mathrm{~K}$. It is a key guidance document for EFB use with applicability to TASAR.

4) AC 20-173, Installation of Electronic Flight Bag Components [13]

5) FAA Order 8110.4C, Type Certification [14]

6) RTCA/DO-160G, "Environmental Conditions and Test Procedures for Airborne Equipment", [15]

Pertains to EMI and High Intensity Radio Frequency (HIRF) requirements for read-only and transmit data interfaces to avionics, respectively. TASAR requires read-only access to avionics, and thus will need to meet EMI requirements (or delegate this requirement to an AID). In addition, TASAR wireless connectivity likely requires additional isolation testing (i.e., TASAR as a Transmit-PED) to ensure noninterference to avionics.

7) AC 20-115, RTCA DO-178B, Software Considerations in Airborne Systems and Equipment Certification [16]

\section{TASAR as a Class 2 EFB}

EFB hardware Classes $(1,2$, or 3$)$ are described in [10]. TASAR is envisioned to be implemented as a Class 2 EFB application. It requires a read-only interface to avionics systems, connection to aircraft power, and data link connectivity for access to ground information sources (refer to Figure 1). TASAR is anticipated to be implemented as a "mounted PED", i.e., a Class 2 EFB. The mounted PED requires interface through an AID. The combination PED EFB and AID represent the Class 2 EFB planned for TASAR. The TASAR EFB must be capable of being easily removed from or attached to its cockpit mount by flight crew personnel. A cockpit mount is planned (versus a yoke mount), for reduced approval requirements. The TASAR EFB with associated AID must be installed in accordance with AC 20-173 [13]. The portable Class 2 EFB components of TASAR are not considered to be part of aircraft type design; i.e., not in the aircraft Type Certificate (TC) or Supplemental Type Certificate (STC).

\section{Class 2 EFB Approval Requirements}

This section examines the approval requirements for a Class 2 EFB hosting a TASAR application.

\section{High-Level Steps for Installation and Operational Approval of a Class 2 EFB}

The following represents the high-level steps needed to be followed for the installation and operational approval of a Class 2 EFB for TASAR:

1) Applicant must obtain approval via TC or STC for initial alterations related to:

a) mounting fixture installation

b) installation of power and/or data connectivity.

2) Manufacturer, provider, or installer must assure via testing that the Class 2 EFB provides interference-free operation. If a data transmitter is used to transmit data to the Class $2 \mathrm{EFB}$, it must be tested to RTCA DO-160G, section 21, paragraph $M$ [15], ensuring conduction/ radiation of emissions do not result in interference.

3) Applicant must obtain TC, STC approval or Designated Engineering Representative (DER) 
approval for installation of antennas that provide data to the EFB, e.g., navigation, weather data.

TASAR falls into this category, as it seeks to access information from network-enabled information services. However, since TASAR is of "No Effect" or "Minor", the data integrity required is expected to be relatively minor. TC, STC, or DER approval requirements of installed antennas are to be determined with further analysis.

\section{FAA Involvement in EFB Approval Process}

FAA offices involved in the EFB approval process are: 1) Certification (AIR), 2) Aircraft Evaluation Group (AEG) - Flight Standards (AFS), and 3 ) the Principal Operations Inspector (POI). The role of AIR is to issue approval of type design of installation for inclusion in the TC/STC. AEG may evaluate new EFBs and prepare an Operational Suitability Report (OSR). The POI conducts reviews and issues authorization by Operational Specification (OpSpec) or by Management Specification (MSpec) and Letter of Authorization (LOA), A061.

\section{Operator Requirements}

The following are requirements to be met by the Operator for the intended function of the EFB, e.g., TASAR:

1) Develops the program for usage

2) Completes an operational evaluation of the new capability

3) Ensures that the system performs its intended function

4) Documents non-interference per AC 91.21-1 [17]

5) Ensures non-interference and isolation from aircraft systems during transmission and reception

6) Determines usage of hardware architectural features, persons, procedures, and equipment to eliminate, reduce, or control risks associated with hardware failure

Note: Installed elements of Class 2 EFBs must be entered into aircraft records when added or removed.

\section{EFB Software Considerations by "Type"}

AC 120-76B [10] provides detailed definitions and description of EFB software related factors (e.g., Type A, B, C; hosted versus approved software). Type A applications (listed in Appendix 1 in [10]) are paper replacement applications intended for use during flight planning on the ground and during noncritical phases of flight. Type B applications (listed in Appendix 2 in [10]) are intended for use during critical phases of flight or have algorithms that must be tested for accuracy and reliability by the applicant.

Sample Type B applications are 1) display of aeronautical charts viewable electronically and allow chart manipulation, 2) Electronic Checklists available in all phases of flight, 3) Weight and Balance calculations/algorithms, 4) performance calculations. These must be tested and proven by the applicant.

While TASAR is currently neither a Type A or Type B application as defined in [10], it has some key characteristics related to Type B software applications: 1) intended for use during flight planning (in case of TASAR, primarily during enroute phase of flight, but potentially during the later stages of climb, and early stages of decent), 2) includes variables in the information presented based on data-oriented software algorithms (in case of TASAR, using a variety of information sources for subsequent processing to determine trajectory change candidates), and 3) Failure Effects Classification of no more severe than "Minor".

While TASAR is similar to a Type B application, it is anticipated that it has a lesser threshold for approval over traditional Type B applications. With TASAR being an optional, supplemental, and advisory support tool, that the flight crew can use at their discretion (i.e., can choose to ignore or disable at any time for any reason), it can be readily viewed as a Type $B$ application. Appropriate pilot training will ensure that the flight crew will not be distracted by TASAR during flight operation while conducting normal and off-nominal operations. As is the case for Type A and B applications, TASAR is not expected to require DO178B software development and certification as part of the approval process. 


\section{Approver and Stakeholder Responsibilities}

The following responsibilities are identified for the various approvers and stakeholders in the approval process of the TASAR EFB Application:

\section{FAA Principal Operations Inspector (POI):}

1) Verifies that:
a) application criteria and operator requirements are met
b) data updates follow maintenance manual and inspection program procedures
c) applicable job aids, including human factors evaluation are completed
d) training, checking, and currency programs are approved
e) operational evaluation report from operator is appropriately reviewed
f) OpSpec or MSpec A061 is issued upon completion of authorization process

2) Ensures that the level of information integrity is commensurate with the Failure Effects Classification of TASAR (i.e., "No Effect" or no more than "Minor") as noted earlier.

Note: As part of the approval process the POI follows detailed checklists found in FSIMS 8900.1 Change 47, Vol. 4, Chapter 15 [12]. Checklist questions are specific to initial installations and training for a given aircraft. Four POI checklists are provided in Figures 4-79 to $4-82$ in [12].

\section{Flight Standards Service (AFS)}

AFS provides initial operational authorization granted for hosted application(s) (e.g., performance, weight and balance applications) based on AIR recommendations and AEG determination of flight crew training, checking and currency requirements.

\section{Operator Requirements}

The Operator must address the following requirements as part of the approval process:

1) Determines usage, architectural features, people, procedures, and equipment to eliminate, reduce, or control risks associated with an identified failure in a system

2) Performs 6-month operational validation per authority granted in OpSpec or MSpec A061
3) Uses both EFB device / system and conventional paper copies during evaluation (not applicable for TASAR)

4) Submits final evaluation report to the POI, as appropriate after evaluation

5) Ensures operating system and hosted application software meet criteria for appropriate intended functions and do not provide false or hazardously misleading information

6) Ensures software revision loading won't corrupt data integrity of original software.

Depending on how the TASAR application will be integrated in a PED / EFB will dictate the level of partitioning required:

1) If TASAR is standalone, with its own dedicated processor (own OS and application software) and dedicated display, this will not require any partitioning or special protections.

2) If TASAR has its own dedicated processor, but shares a common display with other "Approved Software" applications / software (per above definition), recommended Display Standards, e.g., AC 25-11, Electronic Flight Deck Displays (for Part 25 aircraft) [18], and AC 23.1311-1, Installation of Electronic Display in Part 23 Airplanes [19] must be followed.

3) If TASAR is hosted with other approved software applications in a shared processor, approved partitioning techniques must be followed. These techniques are required to guarantee throughput and resources (e.g., memory, hard drive, avionics data) of approved software applications.

\section{PSCP Overview}

In addition to the TASAR EFB hardware and software requirements discussed in the previous section, a review and assessment was made of the requirements and engagement activities with FAA Certification and Operational Approval personnel. Specifically, the makeup of a PSCP was reviewed. To the extent possible, artifacts were identified and TASAR-specific details were identified without fully going through the actual certification process. Subsequent to completion of this assessment of TASAR EFB requirements, development of a PSCP, and development or description of some of the PSCP 
artifacts for TASAR, a dry-run was held with inhouse Rockwell Collins DERs representing software and hardware certification disciplines.

The PSCP represents the composite of both the applicant's and FAA's project plan information as part of the certification and operational approval process. The key element of the PSCP is the Compliance Check List, which indicates that the applicant understands all appropriate regulatory requirements to be satisfied for achieving certification and operational approval. The Compliance Check List provides a summary of the regulatory requirements via reference and points to the type of associated data submittals (i.e., artifacts) that need to be provided to approving authorities.

The PSCP is important as part of the engagement process with FAA for product certification and approval and ensures that the individual elements of the plan take place in proper order and at designated timeframes. This allows for planning of personnel and resources by both the applicant and FAA and provides a roadmap for coordination, information exchanges, and milestone completion dates. Without a well-coordinated PSCP and associated schedule information, the certification project stands little chance for timely completion.

The compilation of TASAR-specific EFB requirements, the make-up of a notional PSCP, and associated artifacts that were developed for the TASAR application were reviewed with two DERs, representing both software and hardware certification disciplines and expertise. Without exception, DER reviewers were in concurrence with the information presented to them for TASAR certification requirements, and offered additional advice, clarification, and perspective on a number of points.

The following certification and operational approval artifacts and requirements were reviewed:

1) Overview of the certification and operational approval plan, i.e., the PSCP

a) Brief overview of the 5 phases of the PSCP, i.e., conceptual design, requirements, compliance planning, implementation, and post certification phases

b) Brief review of the typical content of a PSCP

c) Review of the PSCP as applied to TASAR
2) Review of cornerstone EFB documents (FARs, regulatory, and guidance)

3) Certification approval considerations for the TASAR EFB application, i.e., assumptions, industry trends of EFB applications, key points and observations related to certification approval of the TASAR EFB, and software and hardwarespecific approval considerations and compliance.

\section{Phases of Certification}

1) Conceptual design phase - early activities that define the envisioned product and intended function being considered by the applicant (e.g., concept of operations, use cases and scenarios, human-machine interface, high-level hardware and software sub-system design as preliminary architectures). Identifies new designs, technologies, materials, processes, etc. Includes early formulation of a PSCP. Provides initial safety assessments.

2) Requirements phase - refines and clarifies the product definition and begins development of the PSCP. Applicant develops descriptive design and production data, identifies critical issues. Safety assessments are refined. A proposed certification project schedule is provided.

3) Compliance planning phase - PSCP is completed and agreed to, i.e., signed, in this phase, which establishes the roles of all responsible parties in the certification process. Initial Failure Mode Effects Analysis and safety assessments are provided, critical issues are refined, and production processes are provided. The type certification basis is established and the compliance check list is provided.

4) Implementation phase - the applicant and FAA work to the PSCP and make necessary adjustments as needed to ensure that all agreed to certification requirements are met. Compliance to the FARs, regulations and guidance documents is demonstrated and verified. Analyses, test plans and tests, conformity inspections, flight tests, final safety analyses are completed. If all certification criteria are demonstrated, and verified, the product certification is approved. 
5) Post-certification phase - serves as close-out activities that identify steps to be performed to ensure continued airworthiness of the product.

\section{Elements of the PSCP}

The following is a representative outline of a PSCP amenable for use for TASAR approval:

\section{1) Purpose or Introduction}

Identifies the intent of the certification plan.

\section{2) Description}

Brief description of the system, product and associated application.

\section{3) Federal Aviation Regulations}

Lists applicable regulations by sections, subsections, including the amendment level if it differs from the established certification basis. Plans for exemptions, equivalent levels of safety, or special conditions should be included, if known.

\section{4) Compliance}

States how compliance will be shown; provides analysis results of failures and safety performance. Indicates tests conducted, e.g., qualification, ground, and flight tests. Demonstrates software compliance; design inspection results. Use of unique methodologies should be noted in the certification plans. Compliance data should be part of the certification plan.

\section{5) Conformity}

Identifies parts of the installation required for conformity. Ensures parts are built to specifications.

\section{6) Data}

Lists data to be submitted to show compliance. It is acceptable for report and drawing numbers to be deferred to later.

\section{7) Airplane Flight Manual (AFM)}

Indicate revisions to the AFM if needed.

\section{8) Type Certificate Data Sheet}

Indicates if data sheet needs revision and how.

\section{9) Proposed DER(s)}

Project certification official (ACO) determines appropriateness of assigning designees to represent the FAA, e.g., DER. The ACO may not delegate the authority to approve certain aspects of a project.

\section{0) Master Minimum Equipment List (MMEL)}

Indicates if the MMEL is affected.

\section{1) System Criticality}

For applicable systems, the results of the preliminary function hazard analysis need to be made known, e.g., system criticality, software criticality, functional failure conditions summary.

\section{2) Schedule}

Provide a schedule which shows the following: Significant milestones, when preliminary hazard analysis will be submitted, detail of data submittals (drawings, compliance reports, and test schedule), conformity and airworthiness inspections, compliance inspection schedule, and final approval date anticipated.

\section{FAA Feedback Results}

The NASA TASAR team met with FAA certification (AIR) and operational approval (AFS) representatives to present the analysis results presented in this paper and to gain FAA feedback. The feedback confirmed our analyses and that our assessments were on track. The following is a summary of FAA feedback on the results we provided:

1) TASAR meets the definition of a Type-B application and does not need to be added explicitly to the list of Type B applications in Appendix 2 of [10]. Type-B applications running on non-certified hardware (e.g., Class 2 EFB) do not require DO-178B compliance.

2) TASAR is not considered an "ADS-B IN application" but rather a performance / planning application that leverages ADS-B IN data, if available.

3) No need was identified to establish a TASAR standard.

4) TASAR should be viewed as a "Minor Effect" application because of potential pilot workload associated with TASAR due to misleading/bad data. From a loss of function standpoint, TASAR is viewed as "No Effect." 
5) If an end user already has an existing EFB installation, then the operational approval process is for the user to go directly to the Principal Operations Inspector (POI).

6) Existing policies already cover the proposed TASAR application.

\section{Summary}

This paper illustrated the result of safety analyses and review of the intended function of TASAR in establishing the "No Effect" or "Minor" Failure Effects Classification. EFB Standards Adherence Requirements were reviewed and resulted in determination that TASAR can be implemented as Type B software hosted on a Class 2 PED EFB. An Aircraft Interface Device is also required as part of the cockpit-mount PED EFB to allow interferencefree, read-only access to on-board avionics systems, and to provide data link connectivity via installed antennas for accessible information sources, e.g., weather information, etc. This paper also delineated the roles and responsibilities of the operator, manufacturer, installer, avionics vendor, and FAA certification and operational approvers of newly developed EFB applications, such as TASAR. An overview of the steps that need to be followed as part of a PSCP for achieving approval for TASAR was also provided. Results of TASAR safety, certification and operational approval analyses and assessment were briefed to FAA approvers who generally concurred with our assessment and provided valuable feedback. Based on this feedback, an applicant should have no difficulty in getting approval to implement TASAR from their standpoint.

\section{Ongoing Research and Future Plans}

NASA research on TASAR is continuing and the TASAR EFB application that has been developed is being tested by airline pilots in high-fidelity simulation and in a flight test aircraft operating in ATC-controlled airspace using real-world data flows. The concept, development, analyses, and test results are being documented and will be made available as artifacts to support initial applicants in the FAA approval process. Test and evaluation results are planned to be documented in future reports.

\section{Acknowledgements}

The TASAR research team would like to acknowledge and thank the FAA for the valuable feedback on our certification and operational approval assessment.

\section{References}

[1] Ballin, M.G. and Wing, D.J., "Traffic Aware Strategic Aircrew Requests (TASAR)", AIAA-20125623, AIAA Aviation Technology, Integration, and Operations Conference (Indianapolis, IN, 2012), AIAA, Washington, DC, 2012.

[2] Henderson, J., "Traffic Aware Strategic Aircrew Requests (TASAR) Concept of Operations", NASA/CR-2013-218001, 2013.

[3] Henderson, J. and Idris, H., "Preliminary Benefits Assessment of Traffic Aware Strategic Aircrew Requests (TASAR)", AIAA-2012-5684, AIAA Aviation Technology, Integration, and Operations Conference (Indianapolis, IN, 2012), AIAA, Washington, DC, 2012.

[4] Woods, S, E., Vivona, R.A, Roscoe, D.A, LeFebvre, B.C., Wing, D.J., and Ballin, M.G., "A Cockpit-based Application for Traffic Aware Trajectory Optimization", AIAA Guidance, Navigation, and Control Conference (Boston, MA, 2013), AIAA, Washington, DC, 2013.

[5] SAE International, "Guidelines and Methods for Conducting the Safety Assessment Process on Civil Airborne Systems and Equipment", SAE/ARP 4761, Warrendale, PA, 1996.

[6] Federal Aviation Administration, "System Design and Analysis", Advisory Circular 25.1309-1A, Washington DC, 1988.

[7] Federal Aviation Administration, "System Safety Analysis and Assessment for Part 23 Airplanes", Advisory Circular 23.1309-1E, 2011.

[8] RTCA, "Guidelines for Approval of the Provision and Use of Air Traffic Services supported by Data Communications", RTCA DO-264 / EUROCAE ED78A, Washington, DC, 1992.

[9] Koczo Jr., S., "Analysis of Operational Hazards and Safety Requirements for Traffic Aware Strategic 
Aircrew Requests (TASAR)", NASA Contractor Report, NASA/CR-2013-218002, 2013.

[10] Federal Aviation Administration, "Guidelines for the Certification, Airworthiness, and Operational Use of Electronic Flight Bags", Advisory Circular 120-76B, Washington, DC, 2012.

[11] Title 14 of the Code of Federal Regulations (14 CFR) parts $21,23,25,27,29,43,91 \mathrm{~F}, 91 \mathrm{~K}, 121$, 125 , and 135.

[12] Flight Standards Information System (FSIMS) 8900.1 Change 47, Vol. 4, Chapter 15 - EFB Operational Authorization Process.

[13] Federal Aviation Administration, "Installation of Electronic Flight Bag Components", Advisory Circular 20-173, Washington, DC, 2011.

[14] FAA Order 8110.4C, Type Certification.

[15] RTCA, "Environmental Conditions and Test Procedures for Airborne Equipment", RTCA/DO160G, Washington, DC, 2010.

[16] RTCA, "Software Considerations in Airborne Systems and Equipment Certification", RTCA/DO178B, Washington, DC, 1992.

[17] Federal Aviation Administration, "Use of Portable Electronic Devices Aboard Aircraft", Advisory Circular 91.21.1B, Washington, DC, 2006.

[18] Federal Aviation Administration, "Electronic Flight Deck Displays (for Part 25 aircraft)", Advisory Circular 25-11A, Washington, DC, 2007.

[19] Federal Aviation Administration, "Installation of Electronic Display in Part 23 Airplanes", Advisory Circular 23.1311-1B, Washington, DC, 2005.

32nd Digital Avionics Systems Conference

October 6-10, 2013 